\title{
Coronary Angioplasty in a Low Income Sub-Saharan Country: Situational Analysis
}

\author{
Mouhamed Cherif Mboup1, Djibril Marie Ba2 ${ }^{2}$, Modou Jobe1, Massamba Thiam², \\ Khadidiatou Dia ${ }^{1}$, Pape Diadie Fall ${ }^{1}$ \\ ${ }^{1}$ Hopital Principal de Dakar, Dakar, Senegal \\ ${ }^{2}$ Military Hospital of Ouakam, Dakar, Senegal \\ ${ }^{3}$ Clinique Du Golf, Dakar, Senegal \\ Email:mcmboup@yahoo.fr, ^gaby.11ba@yahoo.fr, modoujobe@gmail.com, massthiam@hotmail.com, \\ khady_dia@yahoo.fr,falldiadie@yahoo.fr
}

How to cite this paper: Mboup, M.C., Ba, D.M., Jobe, M., Thiam, M., Dia, K. and Fall, P.D. (2018) Coronary Angioplasty in a Low Income Sub-Saharan Country: Situational Analysis. World Journal of Cardiovascular Diseases, 8, 539-544.

https://doi.org/10.4236/wjcd.2018.812053

Received: October 30, 2018

Accepted: December 17, 2018

Published: December 20, 2018

Copyright (C) 2018 by authors and Scientific Research Publishing Inc. This work is licensed under the Creative Commons Attribution International License (CC BY 4.0).

http://creativecommons.org/licenses/by/4.0/

\begin{abstract}
Introduction: Coronary angioplasty is not widely conducted in sub-Saharan Africa in general and Senegal in particular. The objective of this work was to describe the indications, techniques, results and difficulties of coronary angioplasty in Senegal. Patients and Methods: We prospectively included all patients who underwent coronary angioplasty between July 2012 and November 2014. We evaluated the clinical characteristics, techniques used, and the peri-procedural complications. Results: 110 coronary angioplasties were performed at the cardiac catheterisation unit of the Clinique du Golf in Dakar. The average age of patients was $60.41 \pm 10.93$ years. A male predominance was noted with a sex ratio of 6.3 . Hypertension was found in $57 \%$ of patients. The principal indications for coronary angioplasty were for the management of acute coronary syndromes with or without ST elevation, in 29 and 39 patients respectively. The femoral artery was the puncture site in 104 patients. The lesions treated were type A/B1 or B2/C in 53 and 57 cases respectively. The success rates of coronary angioplasties and 30-day mortality were $91 \%$ and $0.9 \%$ respectively. Conclusion: In sub-Saharan Africa, Senegal in particular, the practice of coronary angioplasty is low. Indeed, many factors linked to socioeconomic status limit the development of coronary angioplasty in Senegal.
\end{abstract}

\section{Keywords}

Coronary Angioplasty, Acute Coronary Syndrome, Interventional Cardiology

\section{Background}

Coronary angioplasty with stent implantation introduced by Sigwart et al. in 
1986 remains the treatment of choice for coronary atherosclerosis in its various presentations. It is the most common interventional procedure in cardiology with more than 2 million coronary angioplasties done every year worldwide, half of which occur in the United States of America [1] [2]. Advanced equipments, techniques and drugs largely explain the good short and long term prognosis of patients undergoing coronary angioplasty [2]. These technological advancements and increased operators' experience have led to the treatment of increasingly more complex lesions, such as unprotected common trunk, chronic occlusions and bifurcation lesions. Despite its impact on the prognosis of coronary artery disease patients in the short and long term, coronary angioplasty is not widely done in sub-Saharan Africa in general and Senegal in particular. The objective of the present study was to describe the indications, techniques, results and difficulties of coronary angioplasty in Senegal.

\section{Patients and Methods}

The study was carried out at the cardiology department of Hôpital Principal de Dakar and at Clinique du Golf. These two health facilities are both in the Senegalese capital, Dakar.

We prospectively included all patients who underwent coronary angioplasty with or without stent implantation between July 2012 and November 2014. However, patients who underwent only coronary angiography were excluded from the study.

1) Clinical characteristics

We evaluated the patients' age, sex, modifiable cardiovascular risk factors, history of cardiovascular disease and family history of coronary artery disease.

We analyzed the indications for coronary angioplasty: acute coronary syndrome with or without ST segment elevation, stable angina or silent ischaemia.

2) Interventional procedure

We have also evaluated the following activities done during the procedure: the technique used, the characteristics of the lesion according to the ACC/AHA classification, TIMI flow grade, the catheter and guide wire used, the characteristics of the balloon and stent, the stent type (bare or active), the results of angioplasty (success, intermediate success or failure) and complications.

3) Statistical analysis

The parameters studied were entered onto a computerized questionnaire using Epi Info version 6.0. Statistical analysis was performed using with Statistical Package for the Social Sciences (SPSS) software version 14.0.1. Quantitative variables were expressed as mean \pm standard deviation and the qualitative variables were expressed as percentages.

\section{Results}

During the study period, 280 coronary angiographies and 110 coronary angioplasties were performed at the Clinique du Golf in Dakar. 


\section{1) Clinical characteristics}

The average age of patients was $60.41 \pm 10.93$ years. There was a male predominance with a sex ratio of 6.3 (95 males vs 15 females). Hypertension was the commonest cardiovascular risk factor found in $57 \%$ of patients. The prevalence of other risk factors are summarised in Table 1. 20 patients had a history of a myocardial infarction. Among the patients, 12 have had a coronary angioplasty done in Morocco or in France. A history of ischaemic stroke and a peripheral arterial occlusive disease of the lower limbs were found in 2 and 6 patients respectively.

The commonest indications for coronary angioplasty were for the management of acute coronary syndrome, with or without ST segment elevation respectively in 29 and 39 patients. Two patients had a primary angioplasty. The remaining patients were revascularized secondarily after thrombolysis through facilitated angioplasty or after detection of viability respectively in 15 and 12 cases. Other indications for coronary revascularization were effort angina in 38 cases and silent ischemia in 2 patients.

2) Interventional procedure

The femoral artery was the main site of puncture and was used in 104 patients. However, the radial artery was used in 6 patients. The lesions treated were type $\mathrm{A} / \mathrm{B} 1$ or type $\mathrm{B} 2 / \mathrm{C}$ in 53 and 57 cases respectively. A TIMI flow 0 during coronary angiography was present in 23 patients. Five patients had received coronary angioplasty for bifurcation lesion. Table 2 list the materials and technique used during revascularization procedures. The success rate of coronary angioplasties was $91 \%$ (100/110 cases). The main factors of failure were chronic occlusion in 8 cases and calcifications in 2 cases.

The main complications found in our patients were moderate bleeding at the femoral puncture site without hemodynamic consequences but that required transfusion, and one case of acute stent thrombosis. The mortality rate at 30 days was $0.9 \%$ (1 patient).

Table 1. Clinical characteristics and indications for coronary angioplasty.

\begin{tabular}{ccc}
\hline Clinical characteristics & Number & Percentage \\
\hline Average age & $60.41 \pm 10.93$ & \\
Diabetes & 45 & $40.9 \%$ \\
Smoking & 46 & $41.8 \%$ \\
Hypertension & 63 & $57.2 \%$ \\
Dyslipidaemia & 46 & $41.8 \%$ \\
Family history of coronary artery disease & 10 & $9 \%$ \\
History of myocardial infarction & 32 & $29 \%$ \\
History of coronary angioplasty & 11 & $1 \%$ \\
ST elevation acute coronary syndrome & 29 & $26.3 \%$ \\
Non-ST elevation acute coronary syndrome & 39 & $35.4 \%$ \\
Stable angina/silent ischaemia & 42 & $38 . \%$
\end{tabular}


Table 2. Techniques/equipment for coronary angioplasty.

\begin{tabular}{ccc}
\hline Technique for coronary angioplasty & Number & Percentage \\
\hline Femoral artery & 104 & $94.5 \%$ \\
Radial artery & 6 & $5.5 \%$ \\
Anterior interventricular artery & 52 & $47.2 \%$ \\
Circumflex artery & 28 & $25.4 \%$ \\
Right coronary artery & 27 & 24.5 \\
Common trunk & 3 & $2.7 \%$ \\
Bare stent & 82 & $82.8 \%$ \\
Drug eluting stent & 17 & $17.2 \%$ \\
Average length of stent & $17.43+4.4 \mathrm{~mm}$ & \\
Average diameter of stent & $2.9+0.2 \mathrm{~mm}$ & $2.7 \%$ \\
Kissing balloon & 3 & $91 \%$ \\
Volume of contrast & $188.68+63.21 \mathrm{ml}$ & \\
Success of angioplasty & 100 & \\
\hline
\end{tabular}

\section{Discussion}

Coronary angioplasty is an interventional medical procedure widely practised around the world. There are annually more than 2 million angioplasties, with a success rate of $97 \%$, a mortality rate of $0.5 \%$, and a need for urgent coronary surgery of less than $0.5 \%$. Advances in technology and equipments have allowed us to manage more complex lesions such as unprotected common trunk, chronic occlusions and bifurcation lesions. The risk of re-stenosis has been greatly reduced by the use of active stents [3].

However, the practice of coronary angioplasty is not widespread in sub-Saharan Africa. We describe the first set of coronary angioplasties done in Senegal. This practice is still at a low level, indeed in more than 2 years we have carried out only 110 such procedures or an average of 55 angioplasties per year. This low level of activity is correlated with an excess risk of peri-procedural complications. Ellis et al. [4] have shown a strong correlation between the number of patients treated annually by angioplasty and the cumulative risk of serious complications (myocardial infarction, emergency coronary artery bypass surgery, death). Interventional cardiologists treating less than 70 patients per year have an overall rate of serious complications of $9.3 \%$ and being $5.1 \%$ in the subgroup of patients treated for a single lesion (type A or B1 of the ACC/AHA classification). For those treating more than 270 patients a year, the rates are $2.9 \%$ and $1.7 \%$ respectively [4]. However, our success and mortality rates of respectively $91 \%$ and $0.9 \%$ are comparable to Aversano et al. (90.7\% success, mortality $0.9 \%)$ in the United States of America [5]. The indication for coronary angioplasty in our study was mainly for the management of acute coronary syndromes with or without ST segment elevation in $62 \%$ of cases. In a study carried out in France, Mboup et al. found similar indication for angioplasty where $67.9 \%$ of in- 
dications were for the management of acute coronary syndromes [6]. However, in our study primary angioplasty could be performed in only 2 patients. This low primary angioplasty activity is related to the long delay in the management of cases and low health insurance coverage in Senegal. Indeed, the average time to management of myocardial infarction in Dakar is $53.2 \pm 21.3$ hours [7]. The absence of routine coronary artery bypass surgery in Dakar constitutes a real obstacle to care for the most frequent complex lesions such as unprotected common trunk, calcified lesions and bifurcations. Our activity is also limited by the limited availability of disposable equipments. Indeed no industry specializing in interventional cardiology is present in Senegal. A procedure may be postponed for several days due to unavailability of adequate equipment.

\section{Conclusion}

In sub-Saharan Africa, Senegal in particular, the practice of coronary angioplasty is low. The principal indication in our study was for the management of acute coronary syndromes with or without ST segment elevation. The success rate was high and complications were low. However, many factors linked to low socioeconomic status limit the development of coronary angioplasty in Senegal. The expansion of this activity requires an unwavering government support, the development of coronary surgery and establishment of pharmaceutical industry specializing in interventional cardiology.

\section{Conflicts of Interest}

The authors declare no conflicts of interest regarding the publication of this paper.

\section{References}

[1] Singh, M., Rihal, C.S., Gersh, B.J., et al. (2007) Twenty-Five Year Trends In-Hospital and Long-Term Outcome after Percutaneous Coronary Intervention: A Single Institution Experience. Circulation, 115, 2835-2841. https://doi.org/10.1161/CIRCULATIONAHA.106.632679

[2] Roe, M.T., Messenger, J.C., Weintraub, W.S., et al. (2010) Treatments, Trends, and Outcomes of Acute Myocardial Infarction and Percutaneous Coronary Intervention. Journal of the American College of Cardiology, 56, 254-263. https://doi.org/10.1016/j.jacc.2010.05.008

[3] Moses, J.W., Leon, M.B., Popma, J.J., et al. (2003) Sirolimus-Eluting Stents versus Standard Stents in Patients with Stenosis in a Native Coronary Artery. The New England Journal of Medicine, 349, 1315-1323. https://doi.org/10.1056/NEJMoa035071

[4] Ellis, S.G., Weintraub, W., Holmes, D., et al. (1997) Relation of Operator Volume and Experience to Procedural Outcome of Percutaneous Coronary Revascularization at Hospitals with High Interventional Volumes. Circulation, 95, 2479-2484. https://doi.org/10.1161/01.CIR.95.11.2479

[5] Aversano, T., Cynthia, C., Lemmon, R.N., Liu, L., et al. (2012) Outcomes of PCI at Hospitals with or without On-Site Cardiac Surgery. The New England Journal of Medicine, 366, 1792-1802. https://doi.org/10.1056/NEJMoa1114540 
[6] Mboup, M.C., Moquet, B., Zabalawi, A., et al. (2012) Utilisation des stents actifs: Impact des recommandations françaises sur le taux de resténose clinique à deux ans. Annales de Cardiologie et d'Angéiologie, 61, 88-92.

https://doi.org/10.1016/j.ancard.2012.01.002

[7] Mboup, M.C., Diao, M., Kane, A.D., et al. (2011) Délai de prise en charge des syndromes coronariens aigus au Sénégal. A propos de 59 cas. Bull Med Owendo, 13, 13-15. 